\title{
Comparative Study of Cerviprime Gel V/S Intra Vaginal Misoprostol For Second Trimester Abortions
}

\author{
Dr.Eda.Indira ${ }^{1}$, Dr.R.Rama ${ }^{2}$, Dr.B.Srinivas Rao ${ }^{3}$ \\ ${ }^{1}$ Assistant Professors, Department Of OBG, Siddhartha Medical College, \\ Dr.NTRUHS, Vijayawada, Andhra Pradesh.
}

\begin{abstract}
:
Background: The aim of present study was to compare the efficacy and safety of cerviprime gel which is used intracervically/ extra-ovular space with intra vaginal misoprostol 200mcg for second trimester pregnancy termination. It was done on 100 antenatal pregnant women who attended A.N. OPD / ward in Government General Hospital, Guntur seeking second trimester MTP for various reasons.

Materials and methods: Group A (50 cases) cerviprime gel was instilled intracervically followed by oxytocin

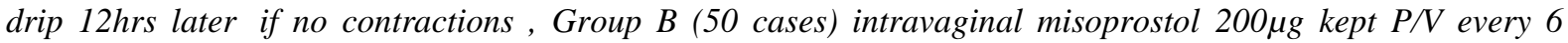
hourly.

Results: The mean induction-abortion interval noted was 23.77 hours in (group A), 16.54 hours in (group B). Complications like vomiting, diarrhea, fever, infection, uterine pain, retained placenta were slightly more in group A when compared to group B. Failures - group A- 9 cases were failed to abort while in group B- 3 cases.

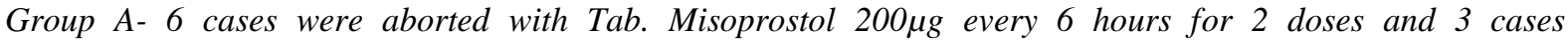
reinstallation of cerviprime gel. In Group B-1 were aborted with oxytocin infusion and 2 cases were aborted with installation of cerviprime gel.
\end{abstract}

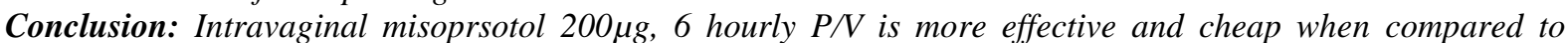
cerviprime gel

Keywords: Mid trimester abortion, Cerviprime gel (PGE2, Dinoprostone gel), Misoprostol, MTP act, Induction abortion interval.

\section{Introduction}

Mid trimester termination of pregnancy is one of the most controversial areas of Gynaecological practice. It has moral, emotional, social and technical issues. There is a continuous need for termination of pregnancy in second trimester, more recently due to increased antenatal diagnostic procedures. Because of inherent morbidity and mortality mid trimester termination of pregnancy done either by surgical or medical methods deserves special importance. Ideal method is still eluding us. It is debatable, which method is safest and most effective and having least complications. No method is simple, safe and optimally effective trails are still going on Dilatation and evacuation is the only acceptable surgical method loosing its popularity due to lack of proper training schedule, its inherent complications and the challenge offered by various medical methods. Now a days, majority of mid trimester abortions are carried out medically.

Every year nearly 80 million unintended pregnancies occur world wide and more than half of these pregnancies nearly 46 millions pregnancies are voluntarily terminated each year, 26 million legally and 20 million outside the legal system. Worldwide induced abortion is the third most common means of fertility control, next to sterilization and O.C pills [1]. Second trimester termination of pregnancy is 12 times more risky than first trimester abortion. Maternal death is lowest with first trimester 0.6 per 1,00,000 with MVA \& Suction Evacuation [2] and death risk is sharply increases to $15-20$ per 1,00,000 for Second trimester legal abortions. Increasingly, women seeking abortion stress their desire to avoid premarital births and to control family size, while de-emphasizing more traditional reasons such as spacing births to protect infant health and some times failure of contraceptive methods like tubectomy and vasectomy. Various methods of second trimester termination of pregnancy have been evaluated.

The development of Prostaglandins is a major breakthrough in abortion technology. Karim and Filshie first reported the use of prostaglandin administration [3]. Cerviprime gel (Dinoprostone gel, PG E2 gel) is used intracevical/ extra-ovular installation of gel will affect collagenase of the cervix and breakdown the collagen network and causes softening and dilatation of cervix followed by uterine contractions. It also sensitizes the myometrium to oxytocin. According to manufacturer guidelines oxytocin induction that follows PG use for cervical ripening should be delayed for 6 to 12 hours following PGE2 administration. Although safe and effective but is expensive and requires refrigeration and storage. Misoprostol is a synthetic analogue of PGE1 developed in 1991-1992 is originally used for treatment of peptic ulcer associated with the use of NSAIDS. It has been widely used although it is not licensed for obstetric use [4] and found to have uterotonic and cervical 
ripening effect as well it is used for termination of pregnancy. It's use in conjunction with mifeprestone in the termination of first trimester and second trimester pregnancy is well established. Using misoprostol alone for second trimester pregnancy termination has been tried by various authors with varying success. It is cheap, stable at room temperature, doesn't need refrigeration and is associated with few complications

\section{Aims and objectives}

1.To compare the efficacy and safety of cerviprime gel (Dinoprostone gel, PGE2 gel) which is introduced intra cervical /extra-ovular space with intravaginal misoprostol for second trimester pregnancy termination.

2. To estimate and describe induction-abortion interval.

\section{Review of Literature}

Abortion is theoretically defined as termination of pregnancy before the fetus becomes viable .This has been fixed administratively at 28 weeks, and the fetus weighs approximately $1000 \mathrm{gms}$. The Indian law (MTP Act, 1971) allows abortion only up to 20 weeks of pregnancy. Abortions are usually categorized as spontaneous and induced spontaneous abortions occur once is every 15 pregnancies. They may be considered as "Nature's method of birth control". Induced abortions, on the other hand are deliberately induced that may be legal or illegal. Illegal abortions are hazardous, they are usually the last resort of women determined to end their pregnancies at the risk of their own lives. The actual incidence of abortion worldwide is not known. Estimates range from 30-55 million a year. In India it has been computed that about 6 million abortions take place every year, of which 4 million are induced and 2 million are spontaneous [5].

Abortion Hazards: Abortions whether spontaneous or induced, whether in the hands of skilled and unskilled persons are always fraught with hazards resulting in maternal morbidity and mortality.

Early Complications: Hemorrhage, shock, sepsis, uterine perforation, cervical injury, pelvic thrombophlebitis, thromboembolism, anaesthetic complications.

Late Sequelae of MTP: Infertility, incompetent os, ectopic pregnancy.

MTP Act of India: Liberalization of the MTP Act was approved by the Indian Parliament in 1971 and was implemented from $1^{\text {st }}$ April 1972 except in Jammu and Kashmir, where it came to effect from $1^{\text {st }}$ November 1976.

\section{Medical Termination of Pregnancy Act 1971 Lays Down}

1. The conditions under which a pregnancy can be terminated.

2. The persons who can perform such terminations.

3. The place where such terminations can be done.

The conditions under which a pregnancy can be terminated under MTP act 1971:

Medical, Eugenic, Humanitarian, Socio-economic, Failure of contraceptives.

\section{The person or persons who can perform such Abortions :}

Up to 12 weeks only a registered medical practitioner having experience in gynaecology and obstetrics can perform abortion. If the pregnancy exceeds 12 weeks and is not more than 20 weeks the opinion of two Registered Medical Practitioners is necessary for terminate the pregnancy.

\section{Where abortions can be done:}

The act stipulates that no termination of pregnancy shall be made at any place other than a hospital established or maintained by government or an institution approved for the purpose of this act by government.

\section{Materials \& Methods}

The study comprises of 100 cases admitted in the Government General Hospital, Guntur, for a period of 2years. For whom Mid trimester abortions include (Fetal Anomalies, Fetal death) requesting for termination of pregnancy 14-20 weeks gestation with a legal valid indication as per MTP Act were taken up for the study. Workup included detailed history, clinical examination, complete blood count, urine analysis, blood grouping, serological screening tests and ultrasonography. Those with previous caesarian section scar, Bronchial asthma, cardiac disease, epilepsy, renal, hepatic diseases were excluded from study. Proforma was filled after taking written consent for termination of pregnancy.

Group A (50 cases): Cerviprime gel -PGE2 gel- 0.5mg, patient was kept in lithotomy position vulva, vagina cleaned with antiseptic lotion and the patient was draped with sterile towel. A sims speculum was introduced into the vagina to retract the posterior vaginal wall and the anterior lip of cervix was caught with the sponge holding forceps. The catheter should be advanced into the cervical canal by direct visualization until the internal os is felt, the contents of the syringe should be emptied slowly by with drawing the catheter this would cause intracervical as well as extra amniotic spread of gel. The patient should be asked to remain supine for at 
least 30 minutes. Signs of progression of abortion was followed after 12 hrs by doing per abdominal and per vaginal examination. If uterine action is week or failed to occur oxytocin drip of 20 units was started in $500 \mathrm{ml}$ of Normal Saline. If dilatation and effacement is poor Inj. Drotin/ Buscopan was given. Those who didn't expel the fetus by $48 \mathrm{hrs}$ were considered as failures. In my study routine reinstallation was not done, but it was done in 3 failure cases.

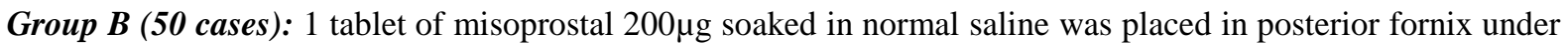
strict aseptic conditions. Patient was asked to confine to bed for 30 minutes. Insertion is repeated every 6 hrs till contractions or till $48 \mathrm{hrs}$. Next dose is differed if she gets more than 3 contractions in 10 minutes each contraction lasting for 40-60 seconds or patient aborts. Antibiotic prophylaxis and Inj. T.T was given to both groups. After completion of process products were examined for completeness and confirmed by per vaginal examination, check ultrasound was done for both groups. The Induction abortion interval and side effects were noted. Failure of procedure was defined as failed expulsion of fetus at $48 \mathrm{hrs}$ or the occurrence of systemic adverse sings and symptoms severe enough to preclude further use of the drug.

\section{Results \& Observations}

Out of the total 100 cases $90-92 \%$ of the women were in the age group of $15-29$ in both groups (Table.1), parity range from $0-3$ are of $96 \%$ in group A, 98\% in group B (Table.2), Almost 66-72\% of cases in both groups from rural area (Table.3) About 9 (18\%) in Group-A , 13 (26\%) in Group-B were unmarried (Table.4). All the cases ranged from 14-20 weeks of pregnancy (Table.5) Mean induction abortion interval in Group-A 23.77hrs, Group-B 16.54hrs (Table.6). 06 cases were aborted in 10-12 hrs with cerviprime gel only without oxytocin infusion. In Group-A 32(64\%), Group-B 45 (90\%) were completely aborted. In Group-A 9 (18\%), Group-B 2(4\%) have incomplete abortion needs check curettage (Table.7). Complications like vomiting, diarrhea, fever, infection, uterine pain were slightly more in Group-A, when compare to Group-B, (Table.8).

Failures : Group-A 9 cases, Group-B 3 cases.

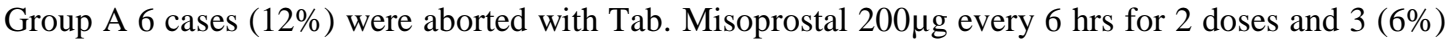
cases reinstallation of cerviprime gel.

Group B $1(2 \%)$ were aborted with Oxytocin Infusion and 2 cases (4\%) were aborted with installation of cerviprime gel.

Table.1Age- Wise Distribution of Cases

\begin{tabular}{|c|c|c|}
\hline Age in years & $\begin{array}{c}\text { Group-A } \\
\text { (Dinoprostone Gel) }\end{array}$ & $\begin{array}{c}\text { Group-B } \\
\text { (Misoprostol) }\end{array}$ \\
\hline $15-19$ & $11(22 \%)$ & $11(22 \%)$ \\
\hline $20-24$ & $22(24 \%)$ & $23(46 \%)$ \\
\hline $25-29$ & $12(24 \%)$ & $12(24 \%)$ \\
\hline Above 30 & $05(10 \%)$ & $04(8 \%)$ \\
\hline
\end{tabular}

$90-92 \%$ of the women were in the age group of 15-29 years, the most fertile period of any women's life.

Table.2 Parity- Wise Distribution of Cases

\begin{tabular}{|c|c|c|}
\hline Gravida & $\begin{array}{c}\text { Group-A } \\
\text { (Dinoprostone Gel) }\end{array}$ & $\begin{array}{c}\text { Group-B } \\
\text { (Misoprostol) }\end{array}$ \\
\hline Primi & $17(34 \%)$ & $19(38 \%)$ \\
\hline $2^{\text {nd }}$ Gravida & $22(44 \%)$ & $22(44 \%)$ \\
\hline $3^{\text {rd }}$ Gravida & $09(18 \%)$ & $08(16 \%)$ \\
\hline $4^{\text {th }}$ Gravida and above & $02(4 \%)$ & $01(2 \%)$ \\
\hline
\end{tabular}

Parity range from 0-3 are of 96\% in Group-A, $98 \%$ in Group-B.

Table.3 Urban and Rural Distribution of Cases

\begin{tabular}{|c|c|c|}
\hline AREA & $\begin{array}{c}\text { Group-A } \\
\text { (Dinoprostone Gel) }\end{array}$ & $\begin{array}{c}\text { Group-B } \\
\text { (Misoprostol) }\end{array}$ \\
\hline Rural & $33(66 \%)$ & $36(72 \%)$ \\
\hline Urban & $17(34 \%)$ & $14(28 \%)$ \\
\hline
\end{tabular}

Almost $66-72 \%$ of cases in both groups are from rural area. The rural \& urban discrepancy in this study indicates the better spread of knowledge regarding the availability of legal abortion among the areas where illegal abortions are rampant. 
Table.4 Marital Status-wise Distribution of Cases

\begin{tabular}{|c|c|c|}
\hline Marital Status & $\begin{array}{c}\text { Group-A } \\
\text { (Dinoprostone Gel) }\end{array}$ & $\begin{array}{c}\text { Group-B } \\
\text { (Misoprostol) }\end{array}$ \\
\hline Married & $34(68 \%)$ & $33(66 \%)$ \\
\hline Unmarried & $09(18 \%)$ & $13(26 \%)$ \\
\hline Widowed/Separated & $07(14 \%)$ & $04(08 \%)$ \\
\hline
\end{tabular}

About 18-26\% were in both groups are unmarried indicating changing sexual trend.

Table.5 Gestation-wise Distribution of Cases

\begin{tabular}{|c|c|c|}
\hline Gestational Age & $\begin{array}{c}\text { Group-A } \\
\text { (Dinoprostone Gel) }\end{array}$ & $\begin{array}{c}\text { Group-B } \\
\text { (Misoprostol) }\end{array}$ \\
\hline $14-16 \mathrm{Wks}$ & $15(30 \%)$ & $20(40 \%)$ \\
\hline $17-20 \mathrm{Wks}$ & $35(70 \%)$ & $30(60 \%)$ \\
\hline
\end{tabular}

All the cases ranged from 14-20 weeks of pregnancy. The cases were selected according to MTP Act.

Table. 6 I.A. Interval as per the G.A( Gestational Age )

\begin{tabular}{|l|c|c|c|c|c|c|}
\hline $\begin{array}{l}\text { Gestational } \\
\text { age }\end{array}$ & Group A & Group B & $\begin{array}{c}\text { Mean I.A Interval } \\
\text { in hours }\end{array}$ & \multicolumn{2}{c|}{ Failures } \\
\hline & & & Group A & Group B & Group A & Group B \\
\hline $14-16$ & 15 & 20 & 23.70 & 15.25 & 3 & 2 \\
\hline $17-20$ & 35 & 30 & 23.79 & 17.36 & 6 & 1 \\
\hline
\end{tabular}

Statistical Analysis :

Chi-square Test : 7.63

P-value : 0.0005

The mean induction abortion interval is considerably reduced in all age groups compared above in Group-B, when compared to Group-A. The failure rate is less in Group-B 3 cases (6\%) than Group-A 9 cases $(18 \%)$.

Table.7 Distribution of cases as per type of abortion

\begin{tabular}{|c|c|c|c|}
\hline & Complete & Incomplete & Failure \\
\hline Group-A & $32(64 \%)$ & $9(18 \%)$ & $9(18 \%)$ \\
\hline Group-B & $45(90 \%)$ & $2(4 \%)$ & $3(6 \%)$ \\
\hline
\end{tabular}

Group-A 64\% are completely aborted whereas in Group B 90\% were aborted completely. Group A $18 \%$ incompletely aborted and in Group B only $4 \%$ are incompletely aborted.

Table.8 Complications in the study

\begin{tabular}{|l|c|c|}
\hline \multicolumn{1}{|c|}{ Complications } & $\begin{array}{c}\text { Group A } \\
\text { (Dinoprostone gel) }\end{array}$ & $\begin{array}{c}\text { Group B } \\
\text { (Misoprostol) }\end{array}$ \\
\hline Vomiting & $6(12 \%)$ & - \\
\hline Diarrhoea & $8(16 \%)$ & $2(4 \%)$ \\
\hline Fever/ Rigors & $2(4 \%)$ & $3(6 \%)$ \\
\hline Haemorrhage & - & - \\
\hline Infection & $2(4 \%)$ & - \\
\hline Uterine pain & $6(12 \%)$ & $3(6 \%)$ \\
\hline Placental Retention & $9(18 \%)$ & $2(4 \%)$ \\
\hline
\end{tabular}

\section{Discussion}

The termination of second trimester pregnancy is a difficult task medically and socially. Ideally speaking a second trimester abortion should not be necessary in a population with wide distribution of contraceptives, or due to other factors, it should be recognized much earlier, and terminated in the first trimester itself. Despite the extensive public education methods taken by Government to avoid termination of pregnancy the problem is not going to be solved within the near future because of lack of education and poverty. In the present study 100 cases were studied for termination of pregnancy in second trimester out of which 50 cases were given intracervical/ extraovular cerviprime gel (Dinoprostone gel) Group-A 50 cases were given intravaginal misoprostal of $200 \mu \mathrm{g}$ every $6 \mathrm{hrly}$ Group B. The mean induction-abortion interval in Group-A $23.77 \mathrm{hrs}$ and Group B 16.54 hrs. Group-B has shorter induction abortion interval, when compare to Group-A. There were 9 (18\%) failures in Group-A, while $3(6 \%)$ in Group-B. The success rate was significantly higher in Group-B 47 
(94\%) than Group-A 41(82\%). Side effects like vomiting in 6 cases (12\%), diarrhoea 8 cases (16\%), fever 2 cases $(4 \%)$, infection 2 cases $(4 \%)$, uterine pain 6 cases $(12 \%)$ were more in Group-A, when compared to Group-B. The placental retention with manual removal was in 9 cases (18\%) who needed curettage in Group-A, curettage was needed only in 2 cases $(4 \%)$ of Group-B. In Group-A most of the cases needed oxytocin supplementation and the Group-B, only few cases needed and it was done without the discomfort of intravenous line. This shows that in our study Group-B (Intravaginal misprostol 200 $\mu \mathrm{g} 6 \mathrm{hrly}$ ) is an efficient successful shorter procedure compared to Group-A (intracervical/ extraovular cerviprime gel).

In our study, Group A mean induction abortion interval was $23.77 \mathrm{hrs}$, and success rate is $82 \%$ which is comparable with the study of Owen et. al. who reported a success rate of $87 \%$ with induction abortion interval of $18 \mathrm{hrs}$, using intracervical dinoprostione gel followed by oxytocin drip[6]. It was also published in 1 to 9 months cum-India's first exclusive vortal on pregnancy as a method of second trimester pregnancy termination using cerviprime gel inserted into the cervix in the evening followed by oxytocin started intravenously as a drip next day morning. Abortion is usually achieved in less than $24 \mathrm{hrs}$ and abortion is complete [7].

The present study in Group-B the mean I-A- interval is $16.54 \mathrm{hrs}$ and success rate is $94 \%$ which is comparable with the study of Dickinson and Evans et.al.,- 2002 the mean I-A Interval is 18.2 hrs and success rate is $92.2 \%$ [8]. It is also compared with the study of John and K.Jain, MD, John K.U.O. and Daniel in their study they have compared two dosing regimens of intravaginal misoprostal for second trimester pregnancy termination. They have administered $200 \mu \mathrm{g}$ of misoprostol intravaginally every $6 \mathrm{hrs}$ and $12 \mathrm{hrs}$. Incidence of abortion within 48 hrs after initial drug administration were $89.2 \%$ and $87.2 \%$, and the mean induction abortion interval was $13.8 \mathrm{hrs}$ and $14.0 \mathrm{hrs}$ in the 6 and $12 \mathrm{hrs}$ groups respectively side effects were similar.

\section{Conclusion}

Approximately $10 \%$ of all pregnancies were terminated in mid trimester. Socio economic, fetal anomalies, IUDs, HIV Infection, unmarried girls and failed contraception pregnancies contribute for majority of mid trimester abortions. Of the two groups studied the Group B (misoprostol group) method is technically simple. No instruments required, cheap, stable at room temperature and cost effective only Rs.10 per tablet. Although both cerviprime gel (dinoprostone gel) and misoprostol are effective for mid trimester termination of pregnancy, Misoprostol is safe, more effective, convenient, cheap and acceptable than cerviprime gel .On going research will further refine the safety, efficacy and optimal dose of misoprostol in mid trimester abortions.

\section{Bibliography}

[1] Sk.Chauduri Textbook of practice of fertility control $7^{\text {th }}$ Edition PageNo. : 238-239.

[2] D.C. Dutta's Textbook of obstetrics $8^{\text {th }}$ Edition Page.No : 207

[3] Karim SMM and Filshe G.M.use of prostaglandin E2 for therapeutic abortion BMJ 1970; 3 : 198-202.

[4] Sabaratnam Arul Kumaran, sarala gopalan, pratap kumar textbook of obstetrics \& Gynecology Volume 1 Third Edition Page.No : 366

[5] Parks Textbook of Preventive and social medicine $21^{\text {st }}$ Edition Page.No: 468

[6] Owen J and Hauth JC. Vaginal misoprostol vs concentrated oxytocin plus low dose prostaglandin E2 for second trimester pregnancy termination. J Maternal fetal Med: 1999; 8(2): 48-50.

[7] 1 to 9 months Com- Indian first exclusive vortal on Pregnancy.8. Dickinson and Evans et.al. AMH Obst. Gynae. Vol. 186, Pg.470-4. 